\title{
RESEARCH
}

\section{Parallel Brain Systems for Learning with and without Awareness}

\author{
Paul J. Reber ${ }^{1}$ and Larry R. Squire ${ }^{2-4}$ \\ ${ }^{1}$ Department of Psychiatry \\ University of California School of Medicine \\ La Jolla, California 92093 \\ ${ }^{2}$ Department of Psychiatry and Neuroscience \\ University of California School of Medicine \\ La Jolla, California 92093 \\ ${ }^{3}$ Veterans Affairs Medical Center \\ San Diego, California 92161-2002
}

\begin{abstract}
A fundamental issue about memory and its different forms is whether learning can occur without the development of conscious knowledge of what is learned. Amnesic patients and control subjects performed a serial reaction time task, exhibiting equivalent learning of an imbedded repeating sequence as measured by gradually improving reaction times. In contrast, four tests of declarative (explicit) knowledge indicated that the amnesic patients were unaware of their knowledge. Moreover, after taking the tests of declarative memory, all subjects continued to demonstrate tacit knowledge of the repeating sequence. This dissociation between declarative and nondeclarative knowledge indicates that the parallel brain systems supporting learning and memory differ in their capacity for affording awareness of what is learned.
\end{abstract}

\section{Introduction}

Memory is not a single faculty but is composed of multiple abilities supported by distinct brain systems (Tulving 1985; Schacter 1987; Weiskrantz 1987; Squire 1992; Schacter and Tulving 1994). A key idea is that some forms of learning and memory are implicit (or nondeclarative) and are expressed through performance without

${ }^{4}$ Corresponding author.

LEARNING \& MEMORY 1:217-229 (C) 1994 by Cold Spring Harbor Laboratory Press ISSN1072-0502/94 \$5.00 requiring access to conscious memory. Perhaps the most familiar example is motor skill learning (Milner 1962; Brooks and Baddeley 1976; Eslinger and Damasio 1986), but nondeclarative memory also includes perceptual and cognitive skills, habits, adaptation-level effects, simple forms of conditioning, and the phenomenon of priming (Schacter et al. 1993; Squire et al. 1993; Seger 1994). Nondeclarative memory, which depends variously on the striatum, cerebellum, amygdala, and neocortex, can be contrasted with declarative memory, which supports conscious recollections about facts and events and depends on the integrity of limbic and diencephalic brain structures (Mishkin and Petri 1984; Thompson 1990; Tulving and Schacter 1990; Squire 1992; Zola-Morgan and Squire 1993).

Another view that has emerged from the study of implicit memory has been that conscious knowledge is invariably available when implicit memory (e.g., skills and habits) is acquired, and that conscious and nonconscious expressions of knowledge simply reflect different uses of a common underlying knowledge base (Dulany et al. 1984; Perruchet and Amorim 1992; Perruchet and Gallego 1993; Whittlesea and Dorken 1993; Shanks and St. John 1994). By this view, when tests are sufficiently sensitive, improvement of performance on an implicit task should always parallel closely the development of conscious knowledge about what is learned.

We have studied the serial reaction time (SRT) task (Nissen and Bullemer 1987; Willingham et al. 1989), which has figured importantly in recent work on implicit learning and awareness (Cohen et al. 1990; Howard et al. 1992; Stadler

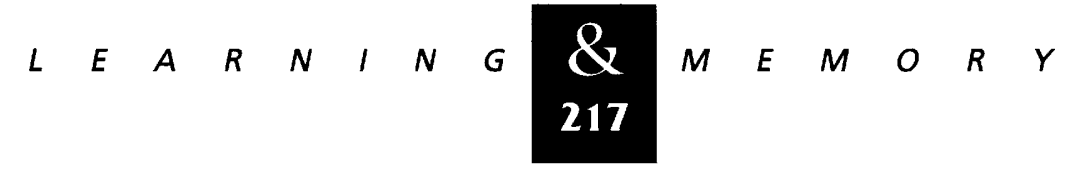


1989; Curran and Keele 1993; Pascual-Leone et al. 1993; Frensch et al. 1994; Reed and Johnson 1994). To assess the capacity for learning this task in the absence of the capacity to develop conscious knowledge about what is learned, we studied amnesic patients, who have selectively impaired declarative memory due to medial temporal lobe or diencephalic brain damage (Schacter et al. 1993; Squire et al. 1993; Seger 1994). Finally, we assessed conscious knowledge for what subjects learned in the SRT task with four different tests that have been used in previous studies of this task (verbal report, prediction, recognition, and generation).

\section{Experiment 1}

\section{Materials and Methods}

\section{SUBJECTS}

AMNESIC PATIENTS

Nine amnesic patients (six men, three women), were tested. For eight of the patients, bilateral diencephalic $(n=6)$ or hippocampal lesions $(n=2)$ have been confirmed by quantitative neuroimaging (Squire et al. 1989, 1990; Polich and Squire 1993; for patients N.F., M.G., and L.J. (L.R. Squire and G.A. Press, unpubl.). The remaining patient (H.W.) had presumed diencephalic damage associated with Korsakoff's syndrome. All patients are well characterized neuropsychologically ( $\mathrm{Ta}$ bles 1 and 2). They averaged 67.9 years of age at the time of the study (range, 59-81) and had an average of 13 years of education. Immediate and delayed (12 $\mathrm{min}$ ) recall of a short prose passage averaged 3.7 and 0 segments, respectively (maximum number of segments, 21; Gilbert et al. 1968). Scores on other memory tests appear in Tables 1 and 2. The mean score on the Dementia Rating Scale was 132.3 [maximum possible score, 144 (Mattis 1976)]. Most of the points that were lost were on the memory subportion of the test (mean points lost $=6.9$ ). The mean score for the Boston Naming Test was 56.2 [maximum score $=60$ (Kaplan et al. 1983)]. Scores for normal subjects on these tests can be found elsewhere (Janowsky et al. 1989; Squire et al. 1990). Two additional amnesic patients were excluded because of their extremely slow reaction times on the first block of the task ( $>1000 \mathrm{msec}$, more than 2.0 s.D. slower than the other subjects), even though they otherwise exhibited good learning of the SRT task.

\section{CONTROL SUBJECTS}

Forty-eight control subjects ( 18 men and 30 women; average age, 64.3; range, 40-77; average education, 14 years) were also tested. They were assigned to three different groups (CON-1, $n=12$; CON-2, $n=12$; Random, $n=24$ ). One additional control subject was excluded because of her slow

Table 1: Characteristics of amnesic patients

\begin{tabular}{lllcccccr}
\hline & & & \multicolumn{7}{c}{$\begin{array}{l}\text { Wge } \\
\text { Patient }\end{array}$} & $\begin{array}{l}\text { WAIS-R } \\
\text { (years) }\end{array}$ & IQ & Lesion $^{\text {a }}$ & & attention & verbal & visual & general & delay \\
\hline N.A. & Dien & 55 & 109 & 102 & 67 & 89 & 68 & 71 \\
M.G. & Dien & 61 & 97 & 92 & 97 & 77 & 89 & 72 \\
R.C. & Dien (K) & 77 & 106 & 115 & 76 & 97 & 80 & 72 \\
N.F. & Dien (K) & 58 & 94 & 91 & 62 & 73 & 53 & $<50$ \\
P.N. & Dien (K) & 66 & 99 & 81 & 77 & 73 & 67 & 53 \\
H.W. & Dien (K) & 76 & 109 & 97 & 84 & 102 & 89 & 54 \\
J.W. & Dien (K) & 57 & 98 & 104 & 65 & 70 & 57 & 57 \\
P.H. & HF & 72 & 115 & 117 & 67 & 83 & 70 & 57 \\
L.J. & HF & 56 & 98 & 105 & 83 & 60 & 69 & $<50$ \\
Mean & & 64.2 & 102.8 & 100.4 & 75.3 & 80.4 & 71.3 & 59.6 \\
\hline
\end{tabular}

The Wechsler Adult Intelligence Scale-Revised (WAIS-R) and the Wechsler Memory Scale-Revised (WMS-R) indices yield a mean score of 100 in the normal population with a S.D. of 15. The WMS-R does not provide scores for subjects who score below 50 . Therefore, the two scores below 50 were scored as 50 for calculating a group mean.

${ }^{\mathrm{a}}$ (HF) Hippocampal Formation; (Dien) diencephalon; (K) Korsakoff's syndrome.

bThe lesion site has not been confirmed radiologically but is supported by the etiology of amnesia (see text).

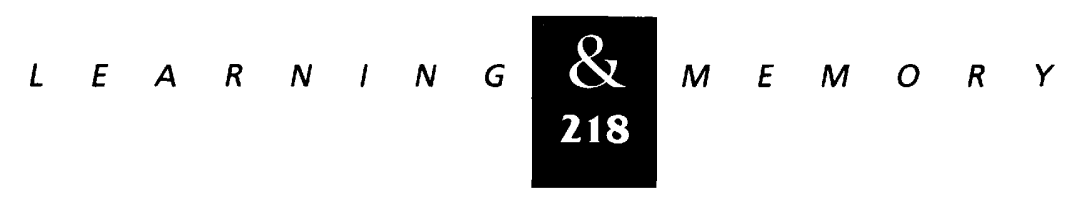


Table 2: Memory test performance

\begin{tabular}{|c|c|c|c|c|c|c|}
\hline Patient & $\begin{array}{l}\text { Diagram } \\
\text { recall }\end{array}$ & $\begin{array}{l}\text { Paired } \\
\text { associations }\end{array}$ & $\begin{array}{l}\text { Word } \\
\text { recall } \\
(\%)\end{array}$ & $\begin{array}{l}\text { Word } \\
\text { recognition } \\
(\%)\end{array}$ & $\begin{array}{l}\text { Words } \\
(50)\end{array}$ & $\begin{array}{l}\text { Faces } \\
(50)\end{array}$ \\
\hline N.A. & 17 & $0-0-2$ & 49 & 93 & 34 & 42 \\
\hline M.G. & 6 & $1-2-8$ & 52 & 89 & 30 & 34 \\
\hline R.C. & 3 & $0-0-3$ & 19 & 85 & 37 & 30 \\
\hline N.F. & 4 & $0-0-2$ & 36 & 76 & 28 & 27 \\
\hline P.N. & 2 & $1-1-1$ & 29 & 83 & 31 & 31 \\
\hline H.W. & 6 & $0-1-0$ & 31 & 85 & 23 & 22 \\
\hline J.W. & 4 & $0-0-2$ & 28 & 96 & 29 & 34 \\
\hline P.H. & 3 & $0-0-1$ & 27 & 84 & 36 & 34 \\
\hline L.J. & 3 & $0-0-0$ & 40 & 93 & 33 & 29 \\
\hline Mean & 5.3 & $0.2-0.4-2.1$ & 34.6 & 87.1 & 31.2 & 31.4 \\
\hline $\begin{array}{l}\text { Healthy } \\
\quad(n=8) \\
\text { Alcoholics }\end{array}$ & 20.6 & $6.0-7.6-8.9$ & 71 & 98 & 41.1 & 38.1 \\
\hline$(n=8)$ & 16.4 & $5.1-8.0-8.8$ & 62 & 97 & 36.2 & 36.2 \\
\hline
\end{tabular}

The diagram recall score is based on delayed (12-min) reproduction of the Rey-Osterrieth figure (Osterrieth 1944; maximum score $=36$ ). The average score for copying the figure was 28.4 , a normal score (Kritchevsky et al. 1988). The paired associate scores are the number of word pairs recalled on three successive trials (maximum score $=10 /$ trial). The word recall score is the percentage of words identified correctly on five successive study-test trials (Rey 1964). The word recognition score is the percentage of words identified correctly by yes/no recognition across five successive study-test trials. The score for words and faces is based on a 24-hr recognition test of 50 words or 50 faces (modified from Warrington 1984; maximum score $=50$, chance $=25$ ). The mean scores for healthy control and alcoholic, nonamnesic subjects shown for these tests are from Squire and Shimamura (1986).

reaction times on the first block of the task (979 msec, $>2.0$ S.D. slower than the other subjects), even though she exhibited good learning of the SRT task.

\section{MATERIALS}

The SRT task was presented on a Macintosh Color Classic II. Four dashes $(0.4 \mathrm{~cm}$ in width and $3.4 \mathrm{~cm}$ apart) appeared continuously $1.2 \mathrm{~cm}$ from the bottom of the screen to denote the possible locations of four cues (A, B, C, D). Each cue was an asterisk $0.4 \mathrm{~cm}$ wide appearing $4.2 \mathrm{~cm}$ above one of the dashes. Responses were made on the computer keyboard, using the four keys "x," "v," "n," and ",", which were directly beneath the four dashes. These keys were marked with red asterisks to indicate where subjects should place their fingers. Subjects used two fingers from each hand, usually the first and second digits, and were instructed to maintain contact with the four keys throughout training. Prior to training, subjects received 20 practice trials with a random sequence.

\section{PROCEDURE}

Cues could appear sequentially in any one of the four locations on the computer screen. Subjects responded to each cue as rapidly as possible by pressing a key directly beneath the cue. Five hundred milliseconds after each response, a cue appeared at a new location. For all four groups (AMN, CON-1, CON-2, and Random), training consisted of 400 trials with $\sim 30$-sec rests after each block of 100 trials (Table 3 ).

SEQUENCE LEARNING I

For the amnesic patients (AMN, $n=9$ ) and one group of control subjects (CON-1, $n=12$ ), a sequence of 10 locations (DBCACBDCBA) repeated every 10 trials throughout training (i.e., 40 
Table 3: Test order for Experiment 1

\begin{tabular}{lcccc}
\hline Test & AMN & CON-1 & CON-2 & Random \\
\hline SRT (Sequence I) & $\mathrm{x}$ & $\mathrm{x}$ & & \\
Verbal report & $\mathrm{x}$ & $\mathrm{x}$ & & $\mathrm{x}$ \\
Prediction & $\mathrm{x}$ & $\mathrm{x}$ & & $\mathrm{x}$ \\
SRT (Sequence II) & $\mathrm{x}$ & $\mathrm{x}$ & $\mathrm{x}$ & \\
Verbal report & $\mathrm{x}$ & $\mathrm{x}$ & $\mathrm{x}$ & $\mathrm{x}$ \\
Recognition & $\mathrm{x}$ & $\mathrm{x}$ & $\mathrm{x}^{\mathrm{a}}$ & $\mathrm{x}$ \\
Generation & $\mathrm{x}$ & $\mathrm{x}$ & $\mathrm{x}$ & $\mathrm{x}$ \\
\hline
\end{tabular}

(x) Each test taken by subjects in each group. (AMN) 12 amnesic patients; (CON-1, CON-2) 12 control subjects each; (Random) 24 subjects given a random sequence. Half of the Random subjects were given the tests in the top panel; the other half were given the tests in the bottom panel.

${ }^{\text {aThe }} \mathrm{CON}-2$ group was given a different recognition test that did not measure explicit knowledge successfully (see text).

repetitions of a 10-trial pattern). Subjects were not told that the training trials contained a repeating sequence. The subjects assigned to the Random group $(n=24)$ received 400 training trials with a random sequence, constructed such that each of the four cue locations appeared equally often ( 100 times each during the $\mathbf{4 0 0}$ training trials).

Immediately following the SRT task, the amnesic patients, the CON-1 group, and 12 of the 24 Random subjects were given two tests of explicit knowledge: verbal report and prediction. (The remaining 12 Random subjects were given three tests of explicit knowledge; see Sequence Learning II, below).

\section{VERBAL REPORT}

Subjects were first asked three questions to determine their appreciation of the repeating sequence: "Do you think the asterisks appeared randomly, or did you think there was some pattern to the sequence?"; "Did the asterisks appear more often in some positions than in others?"; "Did you notice a pattern or repeating sequence?" Subjects who answered the latter question affirmatively were then asked to report the sequence either verbally or by pointing to the screen. Subjects who answered negatively were told, "Suppose for a moment that the asterisks did follow a sequence. Please show me as much of that sequence as you can, even if you have to guess."
PREDICTION TASKS

The first target location of the sequence was presented, and subjects were asked to predict the next target location. Subjects responded at their own pace by pressing the key under the location where they thought the cue would appear next. Subjects were instructed to make their predictions based on how the cues appeared during training. If they guessed correctly, the cue appeared in that location. Otherwise, subjects continued to guess until they were correct. This procedure continued until 200 trials of the training sequence had been presented (i.e., 20 repetitions of the 10 -trial pattern).

SEQUENCE LEARNING II

In a second session ( mean $=73$ days later $)$, the same amnesic patients (AMN), the same control subjects (CON-1), and 12 new control subjects (CON-2), completed 400 training trials with a different repeating sequence (blocks 1-4, BADCDABDAC), followed by three tests of explicit knowledge: verbal report, a recognition memory task, and a generation task. The verbal report task was identical to the one used for Sequence Learning I.

\section{RECOGNITION MEMORY TASK}

Subjects saw five 10 -item sequences presented according to the procedure used for training. One of the sequences was the one presented during training. The other four sequences (foils) were constructed such that within each sequence two cue locations appeared twice and two appeared three times, for example, BDABDCBCAD. After each sequence was presented, subjects rated it from 0 to 100 according to whether they were sure that the sequence had not appeared during training $(0)$ or sure that the sequence had appeared (100). The score was the rating given the correct sequence minus the average rating given the four incorrect sequences. The order of the five sequences was presented to half of the subjects in each group in one fixed order and to half the subjects in the reverse of that order, with the correct sequence always appearing in either the second or fourth positions. The results did not change when the ratings given the first and last sequences (which were always incorrect) were discarded.

The CON-2 group was given a recognition

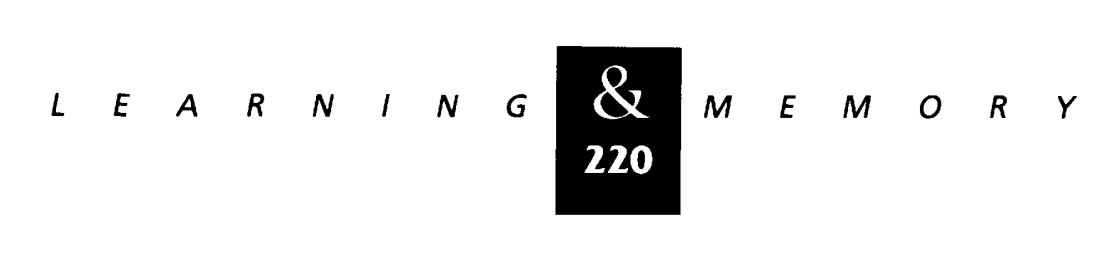


memory test different than the one described here. The recognition test that was used was based on one described by Perruchet and Amorim (1992). Subjects were presented with four-item subsequences drawn from the original training sequence. Subjects saw 10 such target subsequences and $\mathbf{1 0}$ foils (randomly intermixed) and made a yes/no recognition judgment after the presentation of each sequence. Overall control subjects were correct only $\mathbf{5 2 . 5 \%}$ (s.E. 3.0 ) of the time, not significantly different from chance $(t<1.0)$. Because this test did not detect explicit memory in the control subjects, it was not given to the amnesic patients and will not be discussed further.

\section{GENERATION TASK}

Subjects were instructed that the cue would appear above whichever key they pressed. They were then instructed to try to generate a pattern like the one encountered during training. After 100 trials, their responses were scored by counting the number of sequences (length two to eight keystrokes) that had also occurred in the original training sequence. The score for each subject was the sum of the number of sequences from length two to eight keystrokes that were generated (note that on a keystroke that begins a sequence of length eight also begins sequences of lengths seven, six, five, etc.).

SEQUENCE LEARNING II: BLOCKS 5 AND 6

For the amnesic patients and both control groups (CON-1 and CON-2), these three tests of explicit knowledge were followed immediately by an additional 100 trials of training with the same repeating sequence (block 5, BADCDABDAC) and then by a final block of 100 trials with a random sequence (block 6 ).

\section{Results}

\section{SEQUENCE LEARNING I AND II}

Scores for each 100-trial block were calculated as the mean of the median reaction times, excluding errors, for each 10-trial repetition of the sequence. Across both sessions, the amnesic patients made errors on an average of $4.2 \%$ of trials, whereas the control subjects made errors on an average of $2.2 \%$ of trials and the Random group made errors on an average of $3.3 \%$ of trials $[F(2,54)=2.07, P>0.10]$. In the first session, both the control and amnesic groups exhibited knowledge of the sequence as indicated by a gradual decrease in reaction times compared with the Random group (Fig. 1A). Separate analyses of variance (ANOVAs) yielded significant within-subject effects of block $[F(3,93)=6.06, P<0.01$ for AMN vs. Random and $F(3,102)=4.18, P<0.01$ for CON-1 vs. Random] and significant group $\times$ block interactions, $[F(3,93)=10.2, P<0.01$, for AMN vs. Random; $F(3,102)=7.84, P<0.01$, for CON-1 vs. Random]. The group effects were not significant $(F s<1.0)$. A third ANOVA comparing the amnesic and control groups yielded a within-subject effect
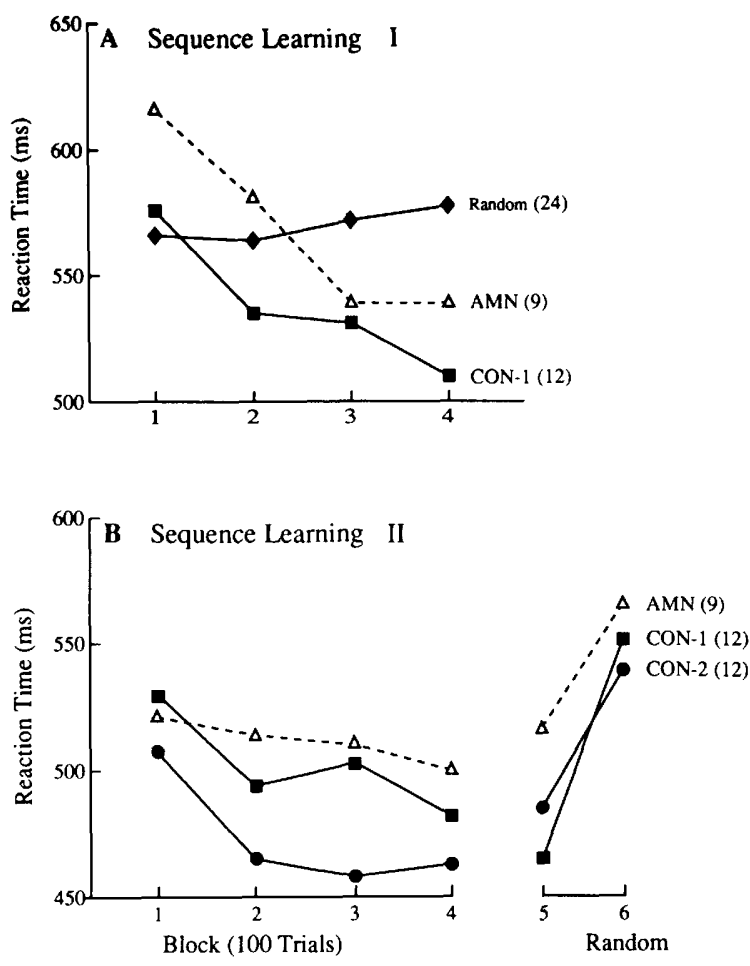

Figure 1: $(A)$ Both amnesic patients $(A M N)$ and control subjects $(C O N-1)$ demonstrated knowledge of the repeating sequence by decreasing their reaction time in comparison to the Random group. (B) The same amnesic patients $(A M N)$ and control group $(\mathrm{CON}-1)$, together with a new control group (CON-2), exhibited knowledge of a second sequence by decreasing their reaction times (left). The increase in reaction times on the final block of random trials (block 6) indicates that knowledge of the repeating sequence was present during block 5 (right). The number of subjects in each group is shown in parentheses. The standard errors of the mean ranged from 21 to $53 \mathrm{msec}$.

$$
\begin{array}{llllllllllllllll}
\boldsymbol{Q} & E & A & R & N & I & N & G & M & E & M & O & R & Y \\
\mathbf{2 2 1} & & & & & &
\end{array}
$$


of block $[F(3,57)=13.0, P<0.01]$ but no effect of group $(F<1.0)$ and no group $\times$ block interaction $(F<1.0)$. Thus, the amnesic patients and control subjects performed similarly.

In the second session (Fig. 1B, left), a $3 \times 4$ ANOVA comparing the amnesic patients and the two control groups with repeated measures across the four blocks indicated improvement across the four blocks $[F(3,96)=5.15, P<0.01]$ but no group effect $(F<1.0)$ and no group $\times$ block interaction $(F<1.0)$. For all three groups, (AMN, CON-1, and CON-2), knowledge of the sequence also persisted after the tests of explicit memory that intervened between the fourth and fifth training blocks, as indicated by the fact that reaction times on the fifth block of training were faster than on the sixth block of random trials (Fig. 1B, right). Thus, learning did not succeed simply because information could be retained in short-term memory, which is intact in amnesia. An ANOVA (two blocks $\times$ three groups) yielded an affect of block $[F(1,30)=37.6$, $P<0.01]$, no group effect $(F<1.0)$, and no block $\times$ group interaction $[F(2,30)=1.36]$.

In the second session the amnesic patients responded incorrectly to the cue on an average of $5.1 \%$ of trials. The control subject groups had average error rates of $1.9 \%$ and $2.3 \%$ (CON-1 and CON-2, respectively). The Random subject group had an average error rate of $4.2 \%$. The difference in error rates was not significant $[F(3,41)=1.48$, $P>0.20]$.

\section{TESTS OF EXPLICIT KNOWLEDGE—VERBAL.} REPORT

For each subject, the score for the verbal report test was the length of the longest segment of the repeating sequence that was reported (Fig. 2A). Amnesic patients (AMN) reported less of the repeating sequence (mean $=2.74$ elements) than either control group [CON-1, mean $=$ 3.91 elements; CON-2, mean $=3.83$ elements; $t s(19)>2.10, P s<0.05]$ and did not differ from the Random group (mean $=2.87$ elements). The scores for AMN and CON-1 are averages for both sessions, and the score for CON-2 is from the second session. The CON-1 group and the AMN group each obtained similar scores across the two sessions. The score for Random subjects, who did not see the repeating sequence, shows the level of performance that can be achieved by chance. A few amnesic patients were unwilling to guess, main-
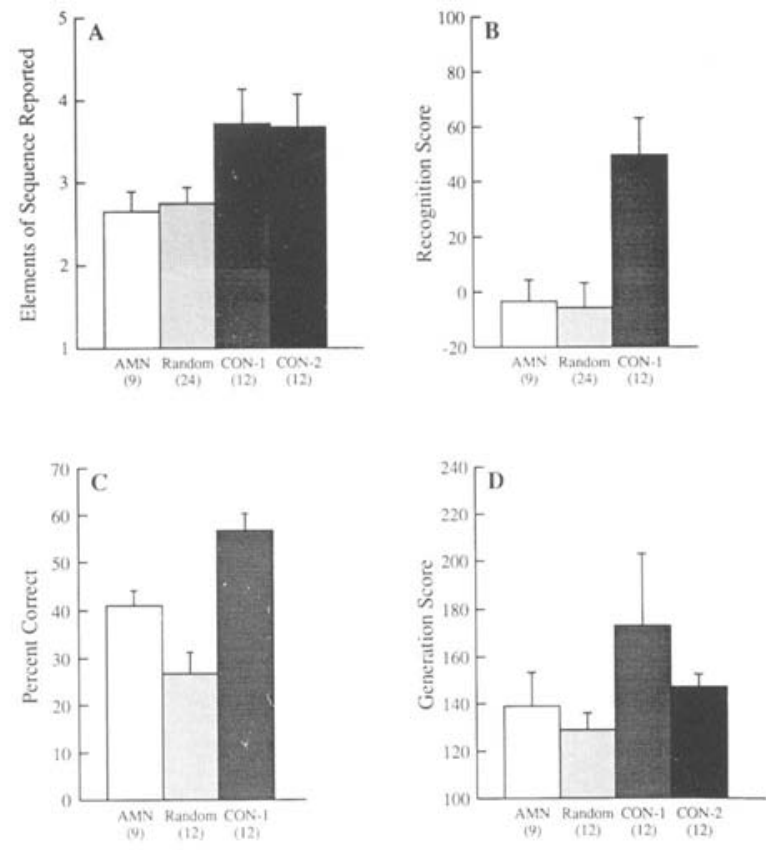

Figure 2: (A) Verbal report. Amnesic patients (AMN) reported less of the repeating sequence than either control group and did not differ from the Random group. $(B)$ Recognition memory of the repeating sequence. Amnesic patients scored lower than $\mathrm{CON}-1$ at recognizing the sequence and similarly to the Random group. (C) Prediction. The score is the number of correct guesses in the first 10 trials. (D) Generation. Performance of the CON-2 group was better than the Random group. The amnesic patients were no better than the Random group but also were not measurably worse than either control group. The number of subjects in each group is shown in parentheses. Vertical rules show standard errors of the mean.

taining that there was no sequence (four in Session 1 and two in Session 2). These patients were assigned the mean score of the Random group for that session. When the occasions on which amnesic patients did not guess were excluded, the AMN score decreased to 2.56 .

Control subjects tended to point to more locations $(7.9 \pm 0.5)$ than the amnesic patients who attempted to report the sequence $(6.6 \pm 1.3)$. Although this difference was not significant $(P=0.13)$, we analyzed the data further by scoring the control subjects (CON-1 and CON-2, $n=24)$ for only the first seven locations of their verbal report (to match the number of locations that the amnesic patients selected). This method resulted in an average score for the control subjects of $3.38 \pm 0.22$ elements of the repeating sequence. 
The random subjects were also rescored, based on the first seven locations of their verbal reports yielding a score of $2.62 \pm 0.18$, and this value was used as a replacement score for the amnesic patients who did not guess. Using these revised measures, the control subjects continued to score marginally higher than the amnesic patients $[t(31)=1.85, P<0.08]$ and higher than the random subjects $[t(31)=2.17, P<0.05]$. Control subjects also scored marginally higher than the amnesic patients when the missing amnesic patient scores (for those who would not guess) were replaced with the mean score of the other amnesic patients $[t(31)=1.85, P<0.08]$. Thus, there was no suggestion in the data that the amnesic patients would have revealed more explicit knowledge about the repeating sequence if they had produced more guesses.

The amnesic patients also differed from control subjects in their appreciation that a repeating sequence had been presented. Specifically, on the three questions that preceded the verbal report task, the amnesic patients responded an average of 1.2 times (averaged across both sessions) that the sequence was nonrandom; the CON-1 group responded 2.3 times that the sequence was nonran$\operatorname{dom}[t(19)=3.44, P<0.01]$. CON-2 subjects responded that the sequence was nonrandom an average of 2.1 times (on the three questions in the second session). The above-zero performance of the amnesic patients is not evidence that they were aware of the sequence, because Random subjects reported the random sequence as nonrandom an average of 1.9 times $(n=24$; each Random subject was given the three questions once, 12 subjects in the first session and 12 subjects in the second seesion).

\section{RECOGNITION MEMORY TEST}

Amnesic patients scored lower (mean score $=-3.5$ ) than the CON-1 subjects (mean score $=49.8)$ at recognizing the sequence that had been repeated during training $[t(19)=3.90$, $P<0.01]$, and they scored similarly to the Random group (mean score $=-5.7$ ) (Fig. 2B).

\section{PREDICTION}

The score is the number of correct guesses in the first 10 trials (Fig. 2C). For the first 10 trials, amnesic patients performed more poorly (mean 4.1 correct predictions) than the control group (mean 5.7 correct predictions) $[t(19)=3.32$, $P<0.01]$ and better than the Random group [ (mean 2.7 correct predictions $t(10)=2.23$, $P<0.05]$. The results were the same for the first 30 trials of the prediction task, after which all three groups began to learn the sequence gradually.

\section{GENERATION}

Performance of the CON-2 group (mean score $=147 \pm 5$ ) was better than the performance of the Random group [ $($ mean score $=129 \pm 7)$ $t(22)=2.08, P<0.05]$ (Fig. 2D). The amnesic patients (mean score $139 \pm 14$ ) were no better than the Random group $(P>0.10)$ but also not measurably worse than either control group [ (mean score for $\mathrm{CON}-1=173 \pm 30$ ) $t s<1.0, P s>0.10$ ]. One subject in CON-1 successfully generated the repeating sequence nine consecutive times, scoring 454 overall. As a result, the variability of the scores in the CON-1 group was high, and this group did not differ from any of the other groups. (The exclusion of this subject's data did not alter the findings.) An alternative scoring method, based on Perruchet and Amorim (1992), was also examined. Specifically, the average number of subsequences that were generated from the 10 -item repeating sequence was examined for each length of the sequence (two to eight) and for each possible starting position ( 70 possible subsequences). None of the comparisons involving these subsequences resulted in significant differences between any of the subject groups.

\section{Experiment 2}

Improved performance on the SRT task has ordinarily been taken to mean that subjects are learning about the repeating sequence. An alternative interpretation of improved performance is that subjects are simply learning to respond quickly in proportion to the frequency with which each location occurs during the training sequence (Shanks et al. 1994). That is, subjects are not learning about sequential information, (i.e., that a particular repeating sequence was presented 40 times during 400 training trials). Instead, they are learning to respond more quickly to locations in the training sequence that are repeated more often

$$
\begin{array}{lllllllllllllll}
\hline & E & A & R & N & I & N & G & \mathbf{Q} & M & E & M & O & R & Y \\
\mathbf{2 2 3} & & & & & & &
\end{array}
$$


than in the random sequence. In the two training sequences that we used (DBCACBDCBA and BADCABDAC), three locations appeared twice every 10 trials and two locations appeared once. In the random sequence, all four locations appeared equally often.

A direct test of the frequency-learning interpretation can be conducted by presenting training trials such that each location in the repeating sequence occurs equally often. In this way, the frequency distribution of the four locations during training is the same as in the random sequence. Any speed advantage of the repeating sequence over the random sequence would indicate that subjects are learning more than just frequency information, that is, sequential probabilities about the structure of the sequence itself.

\section{Materials and Methods}

\section{SUBJECTS}

Eight of the nine amnesic patients who participated in Experiment 1 also participated in Experiment 2. Patient J.W. was not included in Experiment 2 because of his extremely slow reaction times on the first block of the task ( $805 \mathrm{msec}$, $>3.0$ s.D. slower than the other subjects) even though he otherwise exhibited normal learning of the SRT task. Subsequently, we determined that he had been ill.

The 12 control subjects who received a random sequence of trials in the first session of Experiment 1 served as control subjects for Experiment 2 .

\section{MATERIALS}

The SRT task was presented using the same computer equipment as in Experiment 1. A 12 item repeating sequence (BCDBADACABDC) was constructed such that the frequency of locations and the transition frequency between locations was balanced. Specifically, each location occurred three times in the repeating sequence, and each transition (e.g., AB, AC, AD, BA, BC, BD, etc.) occurred once. Accordingly, reaction time improvement on this task could not result simply by learning about frequency or transition frequency. Each 96-trial block of training consisted of eight repeti- tions of the sequence for 96 trials. Four blocks were administered for a total of 384 training trials.

\section{PROCEDURE}

All subjects completed four blocks of training trials with the 12 -item sequence, followed by two tests of explicit knowledge: verbal report and recognition memory. The verbal report task was identical to the one given in Experiment 1. The recognition memory task was identical except that the four incorrect sequences (foils) were all 12-item sequences balanced for frequency. These two tests were followed immediately by an additional block of 96 training trials with the same repeating sequence and then by a final block of 96 trials with a random sequence in which all four locations appeared equally.

\section{Results}

\section{SEQUENCE LEARNING III}

Scores for each 96-trial block were calculated as the mean of the median reaction times, excluding errors, for each 12-trial repetition of the sequence. The amnesic patients made errors on an average of $3.1 \%$ of trials, whereas control subjects made errors on an average of $2.6 \%$ of trials $[F(1,18)<1.0]$. A $2 \times 4$ ANOVA comparing performance of the two groups with repeated measures across the first four training blocks indicated improvement across blocks $[F(3,54)=4.08, P<0.02]$ but no group effect $(F<1.0)$ and no group $\times$ block interaction $(F=1.28)$ (Fig. 3, left). For both groups, knowledge of the sequence also persisted after the tests that intervened between the fourth and fifth training blocks, as indicated by the fact that reaction times on the fifth block of training were faster than on the sixth block of random trials (Fig. 3, right). An ANOVA ( 2 blocks $\times 2$ groups) yielded an effect of block $[F(1,18)=16.1$, $P<0.01$ ], no group effect $(F<1.0)$, and no block $\times$ group interaction $(F=1.36)$. Finally, the block 5 versus block 6 comparison was significant for each group separately [for AMN, $t(7)=2.66$, $P<0.05$; for CON-3, $t(11)=3.67, P<0.01]$.

\section{TESTS OF EXPLICIT KNOWLEDGE-VERBAL REPORT}

As in Experiment 1, the score for the verbal report was the longest segment of the repeating

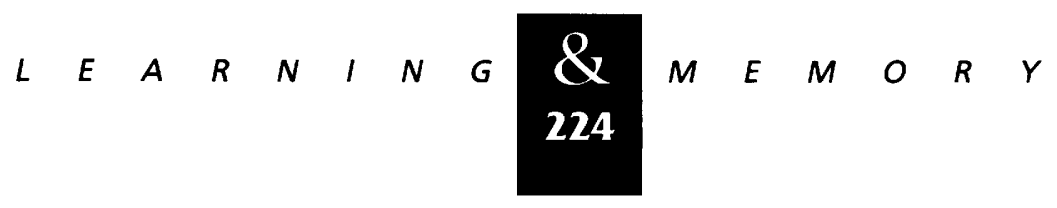




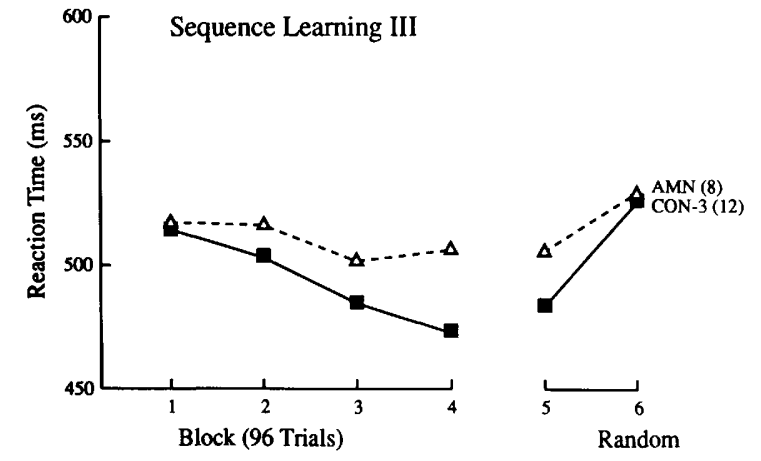

Figure 3: Performance of amnesic patients (AMN) and control subjects $(\mathrm{CON}-3)$ on a 12 -item repeating sequence balanced for the frequency with which the four locations appeared. Both groups exhibited knowledge of the sequence by decreasing their reaction times (left). The increase in reaction times on the final block of random trials indicates that knowledge of the repeating sequence was present during block 5 (right). The number of subjects in each group is shown in parentheses. The standard error of the mean ranged from 15 to $31 \mathrm{msec}$.

sequence that was reported (Fig. 4A). Control subjects reported 3.83 elements of the repeating sequence, significantly more than the 2.69 elements reported by the amnesic patients $[t(18)=2.32$, $P<0.05]$. Three of the amnesic patients were unwilling to guess, maintaining that there was no sequence. To estimate a score for these three patients, the responses that had been made by the control subjects after seeing a random sequence (in Experiment 1, Sequence Learning I) were scored to determine how much of the repeating sequence in Experiment 2 they had generated (by chance). These reports contained an average of 2.83 elements of the 12-item sequence. Accordingly, the three amnesic patients who did not guess were assigned this value as their score for the verbal report test (the mean number of elements reported correctly by the patients who did attempt to report a sequence was 2.60 ). The result was the same when the three patients who did not guess were assigned scores equal to the average of the other patients $[t(18)=2.21, P<0.05]$. Thus, the amnesic patients could report the repeating sequence no better than control subjects who saw a random sequence.

It is unlikely that the results could have been influenced by a lesser willingness of the amnesic patients to select locations. The control subjects selected an average of 8.5 locations, and the amnesic patients who guessed selected an average of 9.4 locations.

\section{RECOGNITION MEMORY TEST}

Neither group demonstrated measurable (above zero) recognition of the repeating sequence (Fig. 4B). The mean score for the amnesic patients was $-2.5 \pm 12$ ); the mean score for the control subjects was $4.1 \pm 12)$. The two groups performed similarly $[t(18)<1.0]$.

\section{Discussion}

Although the amnesic patients learned 10- and 12 -item sequences as well as control subjects (Figs. 1 and 3 ), only the control subjects developed declarative knowledge about what they had learned (Figs. 2 and 4). The control subjects performed better than both the Random group and the amnesic patients on the veral report, recognition memory, and prediction tasks (all $P s<0.05$ ). Overall, with the exception of the prediction task (Fig. 2C), the amnesic patients performed no better than the Random group on any of the tasks. It is important to note that the amnesic patients did not fail the awareness tasks simply because they quickly forgot what they had just learned. Immediately after failing to demonstrate awareness of the sequence, the amnesic patients were able to resume normal performance on the sequence task (Figs. 1 and 3).

Most of the tests designed to assess declarative knowledge successfully detected knowledge of
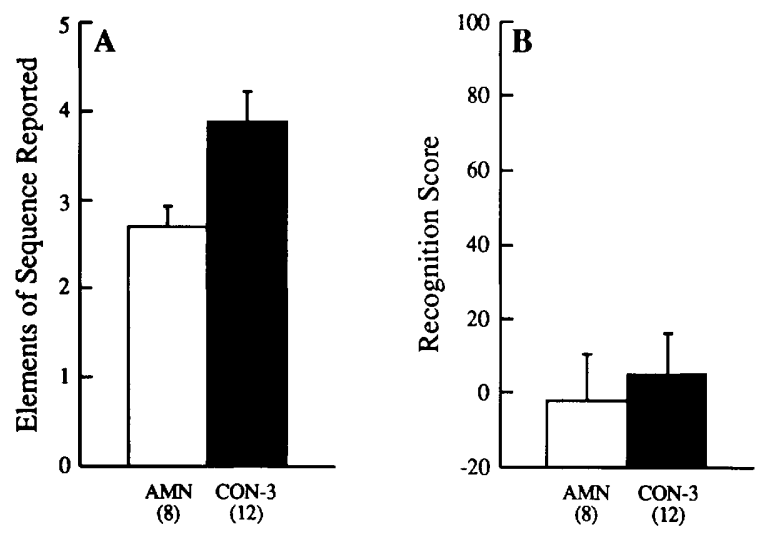

Figure 4: $(A)$ Verbal report. Amnesic patients (AMN) reported less of the repeating sequence than the control subjects (CON-3). (B) Recognition memory. Neither group was able to recognize the repeating sequence in spite of the fact that each group achieved significant knowledge of the sequence as measured by decreased reaction times. Brackets show standard errors of the mean.

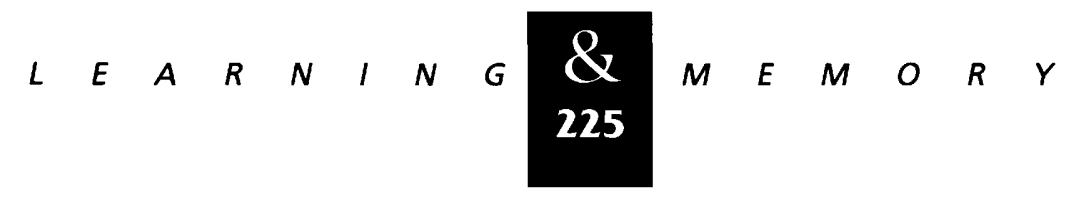


the sequence in the control subjects (all except the Generation task in Experiment 1 and the Recognition task in Experiment 2). Previous work (e.g., Willingham et al. 1989) has also shown that control subjects do not always acquire much declarative knowledge about a repeating sequence. In contrast to the generally good performance of our control subjects, the amnesic patients consistently exhibited impaired or no awareness on every test of declarative knowledge involving three different sequences.

Experiment 2 demonstrated that subjects learned more about the repeating sequence than simply that the four cue locations can appear with different frequencies. Learning also occurred when the four cue locations appeared with equal frequences. These results do not rule out the possibility that frequency learning occurs in this task. However, other information about the sequence must also be acquired (e.g., sequential probabilities).

It is worth mentioning that the same conclusion can be drawn, albeit less directly, from the findings of Experiment 1. Specifically, the slower reaction times on the sixth (random) block (Fig. 1B) demonstrate that subjects had learned more about the repeating sequence than simply that the four cue locations appeared with different frequencies (specifically, locations $A$ and D had occurred three times in each 10-item sequence, and locations B and C had occurred twice). The frequency-learning hypothesis (Shanks et al. 1994) correctly predicts that overall slowing should occur on the sixth block because block 6 contains a different mix of cue locations than block 5 . That is, the two cue locations that were low frequency in blocks 1-5 (and were therefore slower to respond to) are presented relatively more frequency in block 6 than in block 5 (i.e., locations A, B, C, and D now all appear equally often ). The frequencylearning hypothesis, however, does not account for the finding that slowing in block 6 was evident even when reaction times were considered independently for each cue location. The average reaction time to each cue location on the fifth block was $481,549,551$, and $479 \mathrm{msec}$ for locations $\mathrm{A}$, $\mathrm{B}, \mathrm{C}$, and $\mathrm{D}$, respectively. In block 6 , the reaction times to each location increased by $57,65,57,50$ msec for A, B, C, and D [each increase was significant, $t s(32)>2.86 ; P s<0.01]$. These findings, together with the findings from Experiment 2, make it clear that more than frequency information is acquired in the SRT task.
The important finding was that the amnesic patients learned the repeating sequence as well as the control subjects, as measured by their decreasing reaction times, yet they did not exhibit the declarative knowledge of the sequence that the control subjects did. Earlier proposals that learning in healthy subjects can occur without awareness in this task (Cohen et al. 1990; Howard et al. 1992; Curran and Keele 1993; Willingham et al. 1993 ) and in other tasks (Lewicki et al. 1987, 1988; Berry and Broadbent 1988; Reber 1989; Cleeremans and McClelland 1991) have been challenged by evidence from sensitive tests that subjects are not truly unaware of what they have learned (Dulany et al. 1984; Perruchet and Amorim 1992; Perruchet and Gallego 1993; Whittlesea and Dorken 1993; Shanks and St. John 1994). Our control subjects, although they could not describe much of the repeating sequence, were able to demonstrate measurable knowledge of the sequence in aspects of their verbal reports as well as in the prediction test and the recognition memory test. However, the amnesic patients acquired virtually no declarative knowledge about the sequence, as measured by the same tests used in previous studies, but they learned to perform the sequence itself as well as control subjects.

We suggest that control subjects, by virtue of their intact medial temporal lobe and diencephalic memory system, are able to acquire some declarative knowledge about the sequence, but this knowledge is epiphenomenal to sequence learning as measured by improved reaction times. [Note that when normal subjects are able to develop rather complete declarative knowledge about the sequence, such knowledge may be reflected in faster reaction times (Hartman et al. 1989; Willingham et al. 1989) than when normal subjects are only partially aware, as in the present studies.]

Shanks and St. John (1994) have criticized previous studies of amnesic patients that report preserved learning without awareness because these studies did not meet the criteria of "information" and "sensitivity." By their view, these criteria must be met to demonstrate the existence of multiple memory systems that differentially afford awareness. The information criterion stipulates that tests of declarative knowledge must tap the same information as tests of implicit knowledge. In our study of the SRT taks, the information criterion is readily met because all tests rely on knowledge of the repeating sequence. The sensitivity criterion stipulates that the tests of implicit knowledge

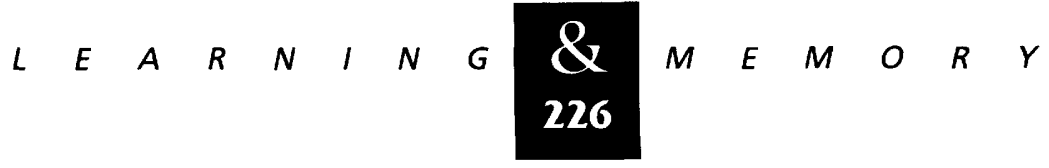


must be at least as sensitive to detecting group differences as tests of declarative knowlege. Our implicit test (the SRT task) was sensitive enough to obtain a difference between amnesic patients and the Random group. We also found that the amnesic patients and control subjects demonstrated equivalent learning in the SRT task. Whereas test sensitivity cannot be estimated from a finding of no difference, it is worth noting that we found amnesic patients and control subjects to be indistinguishable in five separate comparisons involving the SRT task: initial learning of three sequences and performance on two sequences after completion of the tests of declarative knowledge.

In summary, the findings for amnesic patients provide compelling evidence that tacit knowledge can be acquired in the absence of awareness of what is learned. The brain's multiple memory systems provide for separate and parallel learning abilities. Declarative memory affords conscious access to and awareness of what is learned. Nondeclarative memory depends on other brain systems and accumulates tacit knowledge that is expressed through performance and is inaccessible to awareness. The biological and psychological data suggest that the various kinds of information acquired by these memory systems are not stored in a common knowledge base but are acquired in parallel and distributed in multiple memory systems (Squire 1992; Squire et al. 1994). In this sense, memory is analogous to perception, which is also supported by parallel and multiple brain areas (Ungerleider and Mishkin 1982; Goodale 1993).

\section{Acknowledgments}

We thank N. Champagne, B. Kronenberg, and J. Zouzounis for research assistance. This work was supported by the Medical Research Service of the Department of Veterans Affairs, National Institute of Mental Health grant $\mathrm{MH} 24600$, the Office of Naval Research, the McKnight Foundation, and the McDonnell-Pew Center for Cognitive Neuroscience, San Diego, CA.

The publication costs of this article were defrayed in part by payment of page charges. This article must therefore be hereby marked "advertisement" in accordance with 18 USC section 1734 solely to indicate this fact.

\section{References}

Brooks, D.N. and A. Baddeley. 1976. What can amnesic patients learn? Neuropsychologia 14: 111-122.

Berry, D.C. and D.E. Broadbent. 1988. Interactive tasks and the implicit-explicit distinction. Brit. I. Psychol. 79: 251--272.
Cleeremans, A. and J.L. McClelland. 1991. Learning the structure of event sequences. J. Exp. Psychol. Gen. 120: 235-253.

Cohen, A., R.I. Ivry, and S.W. Keele. 1990. Attention and structure in sequence learning. I. Exp. Psychol. Learn. Mem. Cognit. 16: 17-30.

Curran, T. and S. Keele. 1993. Attentional and nonattentional forms of sequence learning. J. Exp. Psychol. Learn. Mem. Cognit. 19: 189-202.

Dulany, D.E., R.A. Carlson, and G.I. Dewey. 1984. A case of syntactical learning and judgment: How conscious and how abstract? J. Exp. Psychol. Gen. 113: 541-555.

Eslinger, P.J. and A.R. Damasio. 1986. Preserved motor learning in Alzheimer's disease: Implications for anatomy and behavior. J. Neurosci. 6: 3006-3009.

Frensch, P.A., A. Buchner, and J. Lin. 1994. Implicit learning of unique and ambiguous serial transitions in the presence and absence of a distractor task. J. Exp. Psychol. Learn. Mem. Cognit. 20: 567-584.

Gilbert, J., R. Levee, and K. Catalano. 1968. A preliminary report on a new memory scale. Percept. Mot. Skills 27: $277-278$.

Goodale, M.A. 1993. Visual pathways supporting perception and action in the primate cerebral cortex. Curr. Opin. Neurobiol. 3: 578-585.

Hartman, M., D.S. Knopman, and M.J. Nissen. 1989. Implicit learning of new verbal associations. J. Exp. Psychol. Learn. Mem. Cognit. 15: 1070-1082.

Howard, D.V. and J.H. Howard. 1992. Adult age differences in the rate of learning serial patterns: Evidence from direct and indirect tests. Psychol. Aging 7: 232-241.

Howard, J.H., S.A. Mutter, and D.V. Howard. 1992. Serial pattern learning by event observation. J. Exp. Psychol. Learn. Mem. Cognit. 18: 1029-1039.

Janowsky, J.S., A.P. Shinamura, M. Kritchevsky, and L.R. Squire. 1989. Cognitive impairment following frontal lobe damage and its relevance to human amnesia. Behav. Neurosci. 103: 548-560.

Kaplan, E.F., H. Goodglass, and S. Weintraub. 1983. The Boston Naming Test. Lea Febiger, Philadelphia, PA.

Kritchevsky, M., L.R. Squire, and J.A. Zouzounis. 1988. Transient global amnesia: Characterization of anterograde and retrograde amnesia. Neurology 38: 213-219.

Lewicki, P., M. Czyzewska, and H. Hoffman. 1987. Unconscious acquisition of complex procedural knowledge. J. Exp. Psychol. Learn. Mem. Cognit. 13: 523-530.

Lewicki, P., T. Hill, and E. Bizot. 1988. Acquistion of

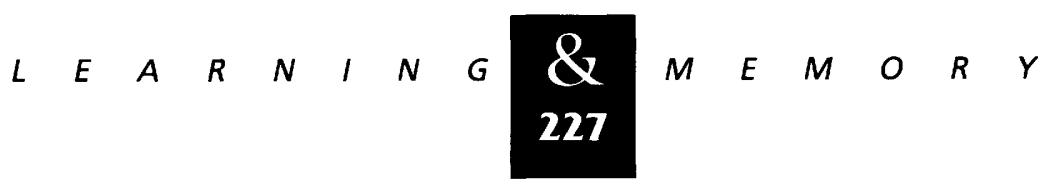


procedural knowledge about a pattern of stimuli that cannot be articulated. Cog. Psychol. 20: 24-37.

Mattis, S. 1976. Dementia Rating Scale. In Geriatric psychiatry (ed. R. Bellack and B. Keraso), pp. 77-121. Grune and Stratton, New York.

Milner, B. 1962. Les troubles de la memoire accompagnant des lesions hippocampiques bilaterales. In Physiologie de I'hippocampe, pp. 257-272. Centre National de la Recherche Scientifique, Paris.

Mishkin, M. and H.L. Petri. 1984. Memories and habits: Some implications for the analysis of learning and retention. In Neuropsychology of memory (ed. L.R. Squire and N. Butters), pp. 287-296. The Guilford Press, New York.

Nissen, M.J. and P. Bullemer. 1987. Attentional requirements of learning: Evidence from performance measures. Cognit. Psychol. 19: 1-32.

Osterrieth, P.A. 1944. Le test de copie d'une figure complexe (The test of copying a complex figure). Arch Psychol. 30: $206-356$.

Pascual-Leone, A., J. Grafman, K. Clark, M. Stewart, S. Massaquoi, J.-S. Lou, and M. Hallett. 1993. Procedural learning in Parkinson's disease and cerebellar degeneration. Ann. Neurol. 34: 594-602.

Perruchet, P. and M. Amorim. 1992. Conscious knowledge and changes in performance in sequence learning: Evidence against dissociation. J. Exp. Psychol. Learn. Mem. Cognit. 18: $785-800$.

Perruchet, P. and J. Gallego. 1993. Association between conscious knowledge and performance in normal subjects: Reply to Cohen and Curran (1993) and Willingham, Greely, and Bardone (1993). J. Exp. Psychol. Learn. Mem. Cognit. 19: $1438-1444$.

Polich, J. and L.R. Squire. 1993. P300 from amnesic patients with bilateral hippocampal lesions. Electroencephalogr. Clin. Neuropsychol. 86: 408-417.

Reber, A.S. 1989. Implicit learning and tacit knowledge. J. Exp. Psychol. Gen. 118: 219-235.

Reed, J. and P. Johnson. 1994. Assessing implicit learning with indirect tests: Determining what is learned about sequence structure. J. Exp. Psychol. Learn. Mem. Cognit. 20: $585-594$.

Rey, A. 1964. L'examen clinique psychologie (The clinical exam in psychology). Presses Universitaires de France, Paris.

Schacter, D.L. 1987. Implicit memory: History and current status. J. Exp. Psychol. Learn. Mem. Cognit. 13: 501-518.

Schacter, D. and E. Tulving. 1994. Advances in the study of memory and memory systems. MIT Press, Cambridge, MA.

Schacter, D.L., C.Y. Chiu, and K.N. Ochsner. 1993. Implicit memory: A selective review. Annu. Rev. Neurosci. 16: 159-182.

Seger, C.A. 1994. Implicit learning. Psychol. Bull. 115: 163-296.

Shanks, D.R. and M.F. St. John. 1994. Characteristics of dissociable human learning systems. Behav. Brain Sci. 17: $367-447$.

Shanks, D.R., R.E. Green, and J. Kolodny. 1994. A critical examination of the evidence for nonconscious (implicit) learning. In Attention and performance XV: Conscious and nonconscious information processing (ed. C. Umlita and $\mathrm{M}$. Moscovitch), pp. 837-860. MIT Press, Cambridge, MA.

Squire, L.R. 1992. Memory and the hippocampus: A synthesis from findings with rats, monkeys, and humans. Psychol. Rev. 99: 195-231.

Squire, L.R. and A.P. Shimamura. 1986. Characterizing amnesic patients for neurobehavioral study. Behav. Neurosci. 100: $866-877$.

Squire, L.R., D.G. Amaral, S. Zola-Morgan, M. Kritchevsky, and G.A. Press. 1989. Description of brain injury in the amnesic patient N.A. based on magnetic resonance imaging. Exp. Neurol. 105: 23-25.

Squire, L.R., D.G. Amaral, and G.A. Press. 1990. Magnetic resonance measurements of hippocampal formation and mammillary nuclei distinguish medial temporal lobe and diencephalic amnesia. J. Neurosci. 10: 3106-3117.

Squire, L.R., B. Knowlton, and G. Musen. 1993. The structure and organization of memory. Annu. Rev. Psychol. 44: 453-495.

Squire, L.R., S. Hamann, and B. Knowlton. 1994. Dissociable learning and memory systems of the brain. Behav. Brain Sci. 17: 422-423.

Stadler, M.A. 1989. On learning complex procedural knowledge. J. Exp. Psychol. Learn. Mem. Cognit. 15: $1061-1069$.

Thompson, R.F. 1990. Neural mechanisms of classical conditioning in mammals. In Behavioural and neural aspects of learning and memory (ed. J.R. Krebs and G. Horn), pp. 63-72. Clarendon Press, Oxford, UK.

Tulving, E. 1985. How many memory systems are there? Am Psychol. 40: 385-398.

Tulving E. and D.L. Schacter. 1990. Priming and human memory systems. Science 247: 301-306.

Ungerleider, W. and M. Mishkin. 1982. Two cortical visual systems. In The analysis of visual behavior (ed. D.J. Ingle, M.A. Goodale, and R.J.W. Mansfield), MIT Press, Cambridge, MA.

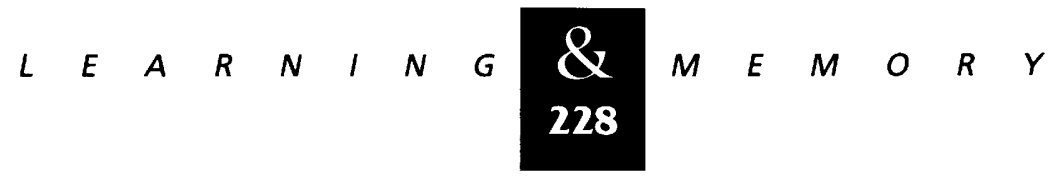


Warrington, E.K. 1984. Recognition Memory Test. FER-Nelson, Windsor, UK.

Weiskrantz, L. 1987. Neuroanatomy of memory and amnesia: A case for multiple memory systems. Human Neurobiol. 6: 93-105.

Whittlesea, B.W.A. and M.D. Dorken. 1993. Incidentally, things in general are particularly determined: An episodic-processing account of implicit learning. I. Exp. Psychol. Gen. 122: 227-248.

Willingham, D.B., M.J. Nissen, and P. Bullemer. 1989. On the development of procedural knowledge. J. Exp. Psychol. Learn. Mem. Cognit. 15: 1047-1060.

Willingham, D.B., T. Greely, and A.M. Bardone. 1993. Dissociation in a serial response time task using a recognition measure: Comment on Perruchet and Amorim (1992). I. Exp. Psychol. Learn. Mem. Cognit. 19: 1424-1430.

Zola-Morgan, S. and L.R. Squire. 1993. Neuroanatomy of memory. Annu. Rev. Neurosci. 16: 547-563.

Received December 7, 1994; accepted in revised form January 27, 1995. 


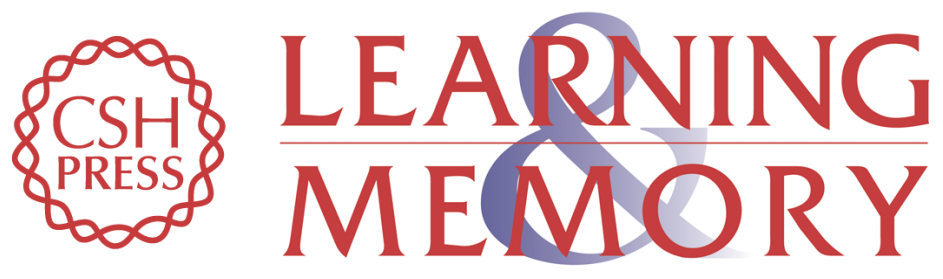

\section{Parallel brain systems for learning with and without awareness.}

P J Reber and L R Squire

Learn. Mem. 1994, 1:

Access the most recent version at doi:10.1101//m.1.4.217

References This article cites 43 articles, 4 of which can be accessed free at: http://learnmem.cshlp.org/content/1/4/217.full.html\#ref-list-1

License

Email Alerting Receive free email alerts when new articles cite this article - sign up in the box at the Service top right corner of the article or click here. 